\title{
Latitudinal changes of euphausiid assemblages related to the morphological variability of the sound scattering layer along Baja California, October 1994*
}

\author{
J. GÓMEZ-GUTIÉRREZ1, G. GONZÁLEZ-CHÁVEZ², C.J. ROBINSON², and V. ARENAS-FUENTES² \\ 1Departamento de Plancton y Ecología Marina, Centro Interdisciplinario de Ciencias Marinas Apartado Postal 592, \\ C.P. 23000 La Paz, Baja California Sur, México \\ ${ }^{1}$ Current address: College of Oceanic and Atmospheric Sciences, Oregon State University, 104 Ocean. Admin. Building. \\ Corvallis, OR 97331-5503, USA \\ ${ }^{2}$ Laboratorio de Ecología de Pesquerías, Instituto de Ciencias del Mar y Limnología, UNAM Apartado Postal 70-305, \\ C.P. 04510. México, D.F., México
}

\begin{abstract}
SUMMARY: Latitudinal changes in the euphausiid assemblages were compared to the morphological structure (size and compactness) of the sound scattering layer (SSL) during ten 24-h surveys made in October 1994 along the west coast of Baja California, México. During October, upwelling was found in the northern area from Punta Eugenia $\left(28^{\circ} \mathrm{N}\right)$ to Ensenada $\left(30^{\circ} \mathrm{N}\right)$ dominated by temperate species from the California Current System. In the southern sector of the peninsula, a northward movement of tropical waters transports a tropical zooplankton assemblage near Bahia Magdalena $\left(24^{\circ} \mathrm{N}\right)$. The aggregation and the dispersion of the whole SSL (plankton and nekton) were investigated using a single beam vertical echosounder, Simrad EY-200, working at $200 \mathrm{kHz}$ and the Hydro Acoustic Data Acquisition System (HADAS) that estimates patch variables of density and compactness. The size and shape of the SSL were obtained from the echogram visualization. The euphausiid species composition was obtained using an Isaacs-Kidd midwater trawl, bongo nets, and openingclosing nets. At Ensenada and Punta Eugenia, an area inhabited by a temperate euphausiid assemblage, large and dense SSLs were recorded over the continental shelf (mean sizes were 10-km and 7-km long with mean compactness of 15\% and 19\%). These regions were dominated by the neritic species Nyctiphanes simplex and the temperate species Nematoscelis difficilis, Euphausia pacifica, and Thysanoessa spinifera. In the southern area, a tropical euphausiid assemblage, dominated by Euphausia eximia, E tenera, and E. distinguenda, inhabits smaller and dispersed SSLs (mean size 5-km long and $11 \%$ compactness) located in the offshore area. The euphausiid biomass of the most abundant species indicated, $N$. simplex and $N$.

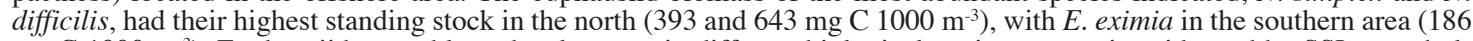
$\mathrm{mg} \mathrm{C} 1000 \mathrm{~m}^{-3}$ ). Euphausiid assemblage development in different biological environments, is evidenced by SSL morphology along the west coast of Baja California during autumn, is caused by strong latitudinal changes in physical oceanography that affect the biological interactions in each region.
\end{abstract}

Key words: Euphausiids, sound scattering layer, Baja California..

\section{INTRODUCTION}

Euphausiids typically play a major role in the economy of the pelagic food web in oceanic and coastal waters. Physical and chemical variables

\footnotetext{
*Received February 18, 1998. Accepted November 12, 1998.
}

related to euphausiid distribution, abundance, and community structure have been studied extensively in the California Current System and Eastern Tropical Pacific (i.e. Brinton, 1962, 1979; Gómez-Gutiérrez, 1995; Gómez-Gutiérrez et al., 1995). However, little attention has been given to the biological interactions between these assemblages and the rest of the pelagic community. 
In the marine pelagic environment, planktonic and nektonic organisms form dense aggregations, hydroacoustically recognized as a Sound Scattering Layer (SSL). This is defined as the layer where a large number of pelagic organisms reflect the hydroacoustic signals. The SSLs are dynamic, active, and have a particular behavior as a function of their community structure causing changes in their vertical distribution, size, and shape over time and space. These variable structures could imply different biological interactions among their components. Pelagic organisms generally form tight aggregations during the day, often near the seabed, and break into less dense aggregations that are more amenable to acoustic observation at night when they move into midwater (Isaacs and Schwartzlose, 1965; Robinson and Gómez-Gutiérrez, 1998).

An insight into the behavior within and between SSLs is important to understand the function of the epipelagic ecosystem. The analysis of echograms provides morphological descriptions of plankton and fish aggregations together with characteristics of their habitat. However, most studies have been made with fish schools (Misund, 1993; Misund et al., 1995; Petigas and Levenez, 1996; Massé et al., 1996). Studies of the SSL using nonintrusive techniques (hydroacoustic) may give clues to the link between euphausiids, the environment, and the rest of the pelagic community.

Along the west coast of Baja California, a strong latitudinal environmental gradient occurs during autumn (Gómez-Gutiérrez et al., 1996, GómezGutiérrez and Robinson, 1997). Because it is known that zooplankton assemblages have latitudinal changes along Baja California during this season (i. e. Brinton, 1962, 1979; Gómez-Gutiérrez et al., 1995, Gómez-Gutiérrez and Robinson, 1997), an interesting comparative study can be performed of the aggregation behavior of the SSLs of temperate and tropical epipelagic assemblages. We hypothesize that temperate and tropical euphausiid community structures inhabit SSLs with different morphological characteristics (i.e. shape, size, and compactness). One of the most important goals of the study of the dynamics of the SSL is the development of models that include animal behavior and environmental factors controlling this behavior. Field sampling on fine horizontal (i.e. $<10 \mathrm{~km}$ ) and vertical scales is important for understanding patch phenomena. Model studies of small regions on fine horizontal scales may help determine how to include the effects of patches in models with coarser spatial resolution.
We designed a sampling program to detect changes on a circadian time scale over about 18 kilometers of the SSL along the Baja California peninsula. The aim of this study was to determine if observed latitudinal changes in the euphausiid community structure during October 1994 (autumn) alters according to the physical characteristics of the SSL along the west coast of Baja California, a region recognized as a transition zone of the California Current System. Studies employing both net sampling and remote techniques could help resolve the spatial and temporal dependence of species distribution, particularly vertical, on an ecosystem scale.

\section{MATERIAL AND METHODS}

Data were collected along the west coast of Baja California, México from October 17 to 30, 1994 on the RV 'El Puma'. Ten 18-km transects perpendicular to the coast, covering three areas, were sampled: north, from Ensenada to Punta Baja; center, from Punta Eugenia to Bahia Asuncion; and south, near Bahia Magdalena (Fig. 1). The transects covered three zones each approximately 6-km long: neritic, slope, and oceanic. Along each transect, there were three oceanographic stations, one at each end and one in the middle (slope zone) (Fig. 1). Each tran-

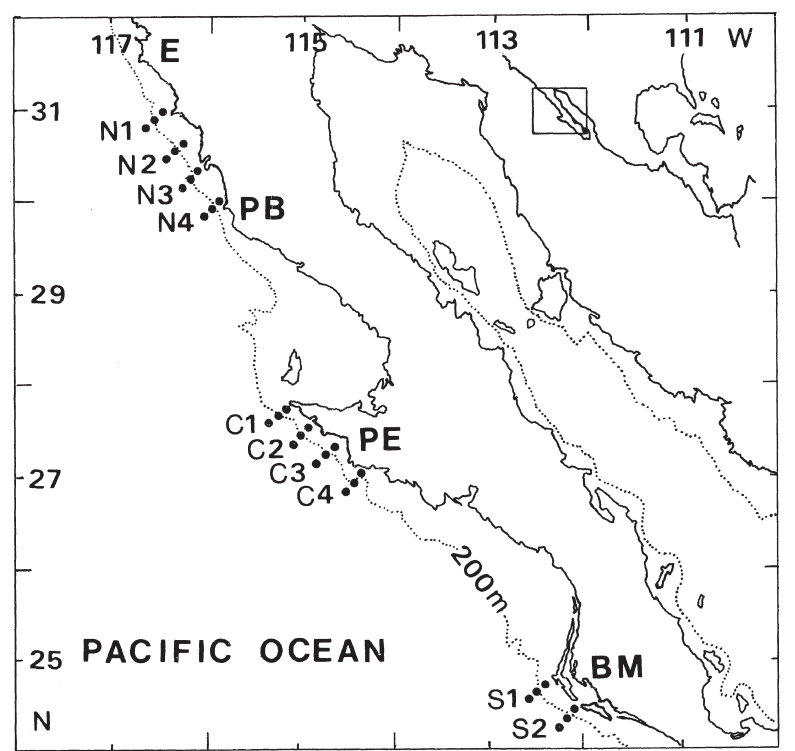

FIG. 1. - Map of the study area, indicating the sampling stations covered during October 1994. $\mathrm{E}=$ Ensenada; $\mathrm{PB}=$ Punta Baja (northern zone, transects 1 to 4 ); $\mathrm{PE}=$ Punta Eugenia (central zone; transects 1 to 4$) ; \mathrm{BM}=$ Bahia Magdalena (southern zone, transect 1 and 2). 
sect was monitored for approximately 24 hours, starting from the neritic station, heading to the oceanic, returning to the middle station and finishing at the neritic station about $4 \mathrm{~h}$ later. The loop was repeated for a total time of $24 \mathrm{~h}$. About six samples (Bongo and CTD) per oceanographic station and about 18 samples per transect were taken.

A continuous hydroacoustic survey of the water column was obtained along each transect. We used a single-beam echosounder, Simrad EY-200 (nominal beam width $7^{\circ}$ ) with a working frequency of 200 $\mathrm{kHz}$, an average ping rate of 1.7 pulses per second, and a pulse duration of $0.3 \mathrm{~ms}$ was used. The transducer depth was $4 \mathrm{~m}$ and the echo analysis started 1 $\mathrm{m}$ from the transducer. Before the cruise, calibration was done using a standard target, a 13-mm diameter copper sphere (-45 decibels $\mathrm{dB}$ ). To analyze the echosounder information, the Hydro Acoustic Data Acquisition System (HADAS) was used (Lindem and Houri, 1988). HADAS processes hydroacoustic data in several steps. First, data are digitized and stored in a data file, later they can be displayed as an echogram and analyzed. This system is an echocounting program that transforms the received echo distribution into area densities and abundance estimates. HADAS uses the Craig and Forbes (1969) algorithm to remove the beam pattern effect.

The hydroacoustic system is able to detect echoes between -32 to $-57 \mathrm{~dB}$ and because a timevaried gain of 40 was used, an analysis of echo counts for individuals was done. Results are presented as individuals per hectare (ind ha- ${ }^{-1}$ ). Moreover, using HADAS it is possible to obtain the number of echoes found as single organism and, therefore, calculates the degree of compactness of the scattering layer. The threshold for a single target is set arbitrarily by the user, but it depends on sound speed, pulse duration in seconds, and the corresponding length of the pulse in meters. In our case, the working pulse duration was $0.3 \mathrm{~ms}$ and the sound speed was $1500-\mathrm{m} \mathrm{s}^{-1}$. The pulse length in the water at any instant was $45 \mathrm{~cm}$. We set ten as the threshold for single targets. That is, if a target lasted for less than 10 echoes it was considered to be a single organism. If it lasted for more, the target was considered a group. Results of compactness were then presented as the percentage of the total number of grouped echoes that were found.

All the hydroacoustical analyses were made using target strengths measuring -53 to $-57 \mathrm{~dB}$. Although the use of a single beam echosounder is not the best method to calculate accurate target strengths (MacLennan and Simmonds, 1992), this echo-strength range was used based on i) results obtained in more than 400 Isaacs-Kidd mid-water trawls that we have made along the west coast of Baja California since 1992, and ii) compared the catches with echo-analysis obtained using the same frequency, the same calibrated echosounder, and the same variables to acquire hydroacoustic data. Accordingly, this target strength corresponds to zooplankton aggregations, mainly euphausiids, which are common in the area (Gómez-Gutiérrez, 1995, Gómez-Gutiérrez and Robinson, 1997; Robinson and Gómez-Gutiérrez, 1998). With this range, we were able to discriminate fish and other larger nektonic animals. Therefore, the rest of the TS range (32 to -52) was neglected in the statistical analyses. When the zooplankton abundance was high enough to be detected by the echo sounder, the acoustic technique detected and quantified the backscattering strength and distribution of the organisms with more detail than is possible with net sampling. Hydroacoustic information, therefore, enabled us to map the vertical and horizontal zooplankton distribution continuously during $24 \mathrm{~h}$.

A modified Isaacs-Kidd mid-water trawl net (a cod end liner of $500-\mu \mathrm{m}$ mesh with a $2.5-\mathrm{x} 2.5-\mathrm{m}$ mouth area) was trawled between stations where dense SSLs occurred to determine the euphausiid species composition. Along each transect, water temperature and salinity were recorded at each oceanographic station using a CTD Inter-Ocean SO4 (from the surface to $200 \mathrm{~m}$ ). Zooplankton samples were collected at each station using Bongo nets fitted with 300- and 500- $\mu \mathrm{m}$ mesh obliquely towed from $200 \mathrm{~m}$ to the surface (or $10 \mathrm{~m}$ from the bottom in more shallow stations). At selected stations, an opening-closing net was trawled at three levels (above, within, and below the thermocline) to detect if the community structure of the shoal is different at these layers. The volumes filtered were estimated using a flowmeter.

The zooplankton biomass was measured as displacement volume and was analyzed using multifactor analysis of variance for latitudinal, cross-shelf, and day vs. night patterns. All euphausiids from the $500-\mu \mathrm{m}$ Bongo net were sorted from the samples, identified to species level, and counted. Numbers were standardized to individuals per $1000 \mathrm{~m}^{-3}$ and $\log$-transformed to normalize them. Euphausiid species were grouped by biogeographic affinities following the classification of Brinton (1979). A cluster analysis (1-Pearson $\mathrm{r}$ using weighted pair- 
group average) was used to determine the grouping based on the presence or absence of species using only samples obtained at night (2000 to 0500) because euphausiids are known to avoid nets during the day. Euphausia diomedeae Ortmann was the only species not included in the analysis because this was caught only during the day.

The total length (from the posterior of the eye to the end of the telson, not including the spines) of all stages of the three most abundant euphausiid species was measured (Nyctiphanes simplex, Nematoscelis difficilis, and Euphausia eximia). To estimate euphausiid biomass in each region, the average body weight by size of these species was estimated as body carbon weight $\left(\mathrm{mg} \mathrm{C} 1000 \mathrm{~m}^{-3}\right)$ calculated from dry-weight equations reported by GómezGutiérrez and Robinson (1997) (Nyctiphanes simplex $\mathrm{DW}=0.005371(\mathrm{TL})^{2.31596}$, Nematoscelis difficilis DW $=0.001892(\mathrm{TL})^{2.87750}$, and Euphausia eximia DW $=0.001057$ (TL) ${ }^{3.10037}$, where DW is dry weight in $\mathrm{mg}$ and $\mathrm{TL}$ is total length in $\mathrm{mm}$ by assuming a carbon content of $45 \%$ (Parsons et al., 1984).

\section{RESULTS}

\section{Environmental conditions}

The temperature-salinity (T-S) diagrams from the neritic and oceanic zones in the three latitudinal areas are shown in Figure 2. Strong latitudinal changes were evident along the west coast of Baja California. Surface waters of the California Current dominated the northern area with temperatures $<18$ ${ }^{\circ} \mathrm{C}$ and salinity $<33.4 \mathrm{ppt}$ in the 50 -m surface layer, the salinity increasing to about $34.3 \mathrm{ppt}$ in deeper waters. The environmental conditions from the neritic and oceanic stations were quite different with lower temperature and slightly more saline water inshore indicating upwelling near shore. The decrease in minimum subsurface salinity can be assumed to be caused by the greater influence of California Current waters. In the center area, the 50m layer was warmer $\left(18\right.$ to $20^{\circ} \mathrm{C}$ ) and saltier (about $34.6 \mathrm{ppt}$ ) than the northern area. Like the north, in the center zone a neritic-oceanic gradient was evident. A body of cool water was present inshore between $27^{\circ}$ and $30^{\circ} \mathrm{N}$, a feature perhaps indicative of recent upwelling. The southern area showed a marked influence of the Equatorial surface water mass with warmer surface waters $\left(24-25{ }^{\circ} \mathrm{C}\right.$ within
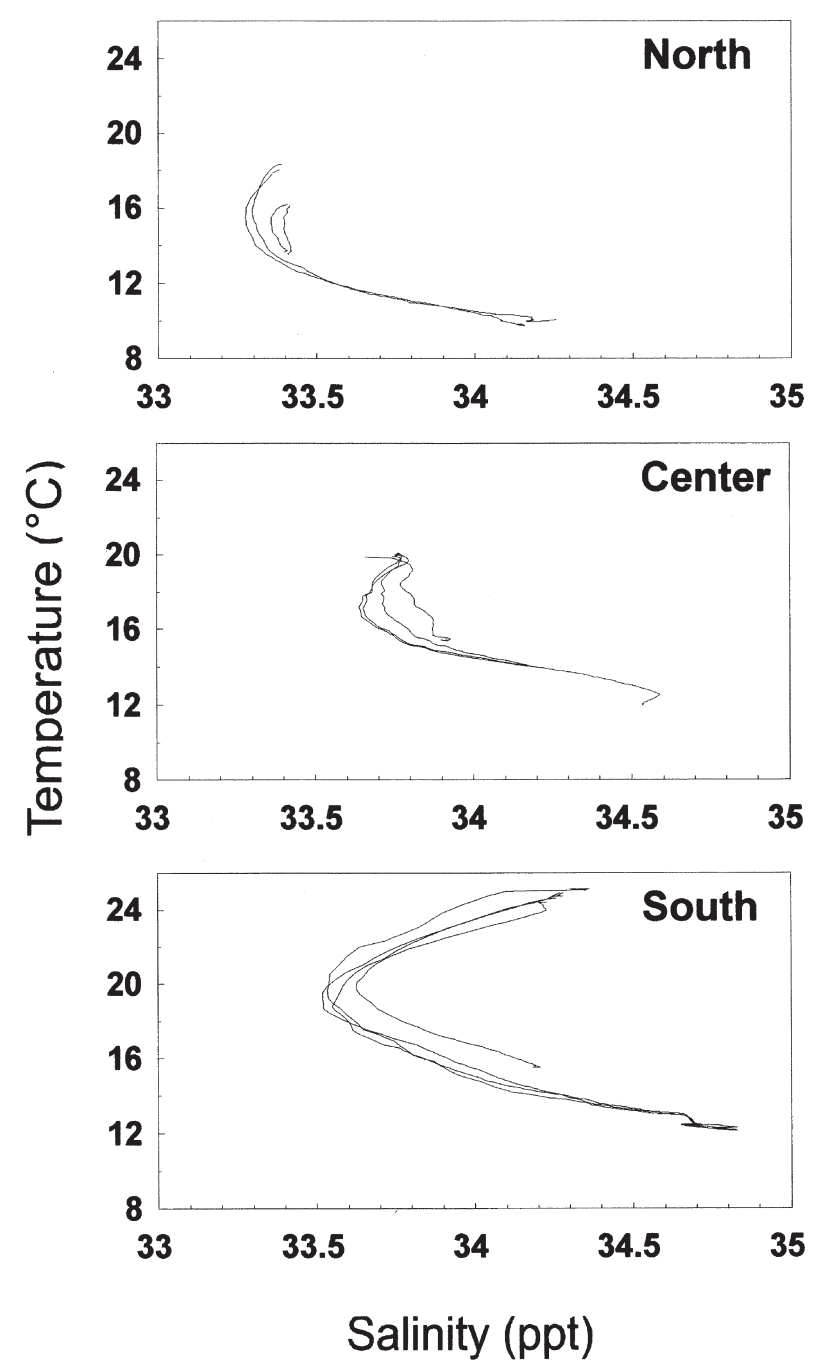

FIG 2. - Representative temperature-salinity (T-S) diagrams for different latitudinal zones, North = Ensenada; Center = Punta Eugenia, and South $=$ Bahia Magdalena during October 1994. At each latitudinal zone, a neritic and an oceanic CTD vertical profile at night and another two during the day were chosen.

the first $25 \mathrm{~m}$ ) corresponding to surface Equatorial waters (Fig. 2).

\section{Community structure of the euphausiids}

Zooplankton samples from the Isaacs-Kidd midwater net trawls were dominated by seven euphausiid species (Table 1). All the other four euphausiid species were less than $8 \%$ of the total euphausiid abundance and, therefore, were grouped. Nyctiphanes simplex was the most abundant euphausiid collected with net gear in the north and central area and the second most abundant in the southern area, after Euphausia eximia. Using biogeographical affinities proposed by Brinton (1979), we found the north and central zones dom- 
TABLE 1. - Average density (ind $\mathrm{dm}^{-3}$ ) of the euphausiid species obtained by Isaacs-Kidd net trawls along the west coast of Baja California, México during October 1994. Relative abundance $(\%)$ is shown in parentheses, $n=$ number of Isaacs-Kidd trawls analyzed, and $*=$ species found in only one sample.

\begin{tabular}{|c|c|c|c|c|c|c|}
\hline \multirow[t]{2}{*}{ Species } & \multicolumn{2}{|c|}{ North $(n=5)$} & \multicolumn{2}{|c|}{ Center $(n=5)$} & \multicolumn{2}{|c|}{ South $(n=6)$} \\
\hline & Average & SD & Average & $\mathrm{SD}$ & Average & SD \\
\hline Nyctiphanes simplex & $4049(84.57)$ & 1844 & $7625(60.02)$ & 13603 & $4206(40.65)$ & 6626 \\
\hline Thysanoessa spinifera & $333(6.95)$ & $*$ & & & & \\
\hline Nematoscelis difficilis & & & $266(2.09)$ & $*$ & & \\
\hline Nematobrachion flexipes & & & $66(0.51)$ & $*$ & & \\
\hline Euphausia pacifica & & & $3730(29.36)$ & 4804 & & \\
\hline Euphausia eximia & & & $266(2.09)$ & $*$ & $5183(50.08)$ & 7477 \\
\hline Euphausia tenera & & & & & $466(4.51)$ & * \\
\hline Others species (four) & $406(8.48)$ & 409 & $753(5.93)$ & 879 & $493(4.76)$ & 445 \\
\hline
\end{tabular}

inated by the marginal eastern tropical Pacific proliferator (ETP) N. simplex; three temperate California Current terminus species, (Nematoscelis difficilis, Thysanoessa spinifera, and Euphausia pacifi$\mathrm{ca}$ ) and several species of the offshore section of the California Current. In the southern zone, $N$. simplex and Euphausia eximia, another marginal ETP proliferator species, dominated, followed by two tropical and equatorial endemic ETP-adapted species (Euphausia tenera and Euphausia distinguenda). Excluding N. simplex, N. difficilis, and Stylocheiron affine, the euphausiid composition in the three latitudinal regions showed strong latitudinal differences (Table 1).
Nineteen euphausiid species were caught in the Bongo trawls, showing a higher diversity than the Isaacs-Kidd net trawls. However, similar latitudinal trends in community structure of the euphausiids were observed. Changes in the species list were noted between latitudinal regions, and the relative abundance of species varied (Table 2). For example, Nyctiphanes simplex had its highest abundance when caught with a Bongo net in the north area, decreasing toward the south. Whereas, the catch using the Isaacs-Kidd net had its highest abundance in the center area. Nematoscelis difficilis abundance peaked in the north area using the bongo nets, but it was present only in the center area when caught in the

TABLE 2. - Average of sea surface temperature $\left({ }^{\circ} \mathrm{C}\right)$, zooplankton biomass $\left(\mathrm{ml} 1000^{-3}\right)$, and abundance (ind $\left.1000 \mathrm{~m}^{-3}\right)$ of the euphausiids obtained by Bongo net trawls along the west coast of Baja California, México. Relative abundance is shown in parentheses. $*=$ abundance $<0.005$ ind $1000 \mathrm{~m}^{-3}$.

\begin{tabular}{|c|c|c|c|c|c|c|}
\hline \multirow[t]{2}{*}{ Zone } & \multicolumn{2}{|c|}{ North $\left(29-31^{\circ} \mathrm{N}\right)$} & \multicolumn{2}{|c|}{ Center $\left(26-28^{\circ} \mathrm{N}\right)$} & \multicolumn{2}{|c|}{ South $\left(24-25^{\circ} \mathrm{N}\right)$} \\
\hline & Day $(n=41)$ & Night $(n=27)$ & Day $(n=44)$ & Night $(n=33)$ & Day $(n=20)$ & Night $(n=17)$ \\
\hline SST & 18.12 & 17.83 & 20.32 & 19.99 & 25.34 & 25.21 \\
\hline Biomass $500 \mu \mathrm{m}$ & 40.33 & 47.00 & 63.35 & 74.02 & 19.98 & 29.87 \\
\hline Biomass $300 \mu \mathrm{m}$ & 59.80 & 84.59 & 80.27 & 74.34 & 25.35 & 28.50 \\
\hline Nyctiphanes simplex & $43.82(92.21)$ & $24.49(77.72)$ & $23.78(96.76)$ & $29.73(94.32)$ & $1.22(18.96)$ & $0.54(3.47)$ \\
\hline Nematoscelis difficilis & $2.58(5.43)$ & $4.61(14.63)$ & $0.18(0.73)$ & $0.66(2.09)$ & $0.05(0.81)$ & $0.04(0.24)$ \\
\hline Stylocheiron affine & $0.19(0.40)$ & $0.16(0.50)$ & $0.27(1.10)$ & $0.48(1.54)$ & $0.36(5.59)$ & $0.82(5.24)$ \\
\hline Stylocheiron longicorne & $0.03(0.03)$ & $0.03(0.10)$ & & & & \\
\hline Stylocheiron maximun & $*(0.01)$ & $*(0.01)$ & & & & \\
\hline Euphausia hemigibba & & $*(0.01)$ & & & & \\
\hline Euphausia pacifica & $0.50(1.05)$ & $0.99(3.14)$ & & $*(0.01)$ & & \\
\hline Euphausia gibboides & $0.27(0.57)$ & $0.91(2.90)$ & $*(0.02)$ & $0.04(0.12)$ & & \\
\hline Euphausia recurva & $0.01(0.01)$ & & & $0.01(0.02)$ & & \\
\hline Stylocheiron abbreviatum & $0.03(0.06)$ & $0.03(0.09)$ & $*(0.01)$ & & & \\
\hline Thysanoessa gregaria & $0.08(0.17)$ & $0.09(0.28)$ & $*(0.01)$ & $0.03(0.11)$ & & \\
\hline Thysanoessa spinifera & & $0.16(0.52)$ & $*(0.01)$ & & & \\
\hline Nematobrachion flexipes & & $0.01(0.03)$ & $*(0.01)$ & $0.02(0.06)$ & & $0.01(0.09)$ \\
\hline Euphausia eximia & $0.01(0.02)$ & $0.02(0.07)$ & $0.33(1.35)$ & $0.54(1.73)$ & $4.34(67.65)$ & $12.58(80.14)$ \\
\hline Nematoscelis tenella & & & & $*(0.01)$ & & \\
\hline Nematoscelis gracilis & $*(0.01)$ & & & & $0.18(2.85)$ & $0.62(3.92)$ \\
\hline Euphausia distinguenda & & & & & $0.05(0.84)$ & $0.26(1.64)$ \\
\hline Euphausia tenera & & & & & $0.20(3.14)$ & $0.83(5.27)$ \\
\hline Euphausia diomedeae & & & & & $0.01(0.16)$ & \\
\hline Total & 47.52 & 31.52 & 24.58 & 31.52 & 6.41 & 15.70 \\
\hline
\end{tabular}


TABLE 3. - Mean abundance of the scattering layer recorded hydroacoustically by an echosounder, Simrad EY-200, (200 kHz), by latitudinal zone. Abundance is expressed as individuals per hectare using a target strength range between -53 to $-57 \mathrm{~dB}$. $n=$ number of echograms analyzed.

\begin{tabular}{|c|c|c|c|c|}
\hline Zone and Transect & $\begin{array}{c}\text { Day } \\
\text { ind ha }^{-1}\end{array}$ & $\begin{array}{l}\text { Night } \\
\text { ind } \text { ha }^{-1}\end{array}$ & $\begin{array}{l}\text { Day and Night } \\
\text { ind ha }{ }^{-1}\end{array}$ & $\begin{array}{c}\text { Relative } \\
\text { abundance (\%) }\end{array}$ \\
\hline $\begin{array}{l}\text { North } 1(n=6) \\
\text { North } 2(n=7) \\
\text { North } 3(n=7) \\
\text { Mean }\end{array}$ & $\begin{array}{r}916 \\
11416 \\
95521 \\
35951\end{array}$ & $\begin{array}{r}1910 \\
18800 \\
91852 \\
37521\end{array}$ & $\begin{array}{r}2826 \\
30216 \\
187373 \\
73472\end{array}$ & $\begin{array}{r}1.3 \\
14.1 \\
84.6 \\
55.4\end{array}$ \\
\hline $\begin{array}{l}\text { Center } 1(n=6) \\
\text { Center } 2(n=6) \\
\text { Center } 3(n=7) \\
\text { Center } 4(n=6) \\
\text { Mean }\end{array}$ & $\begin{array}{r}7969 \\
16966 \\
8744 \\
40030 \\
18427\end{array}$ & $\begin{array}{l}18058 \\
13580 \\
17084 \\
44949 \\
23418\end{array}$ & $\begin{array}{l}26027 \\
30546 \\
25828 \\
84979 \\
41845\end{array}$ & $\begin{array}{l}15.5 \\
18.3 \\
15.5 \\
50.7 \\
31.5\end{array}$ \\
\hline $\begin{array}{l}\text { South } 1(n=7) \\
\text { South } 2(n=5) \\
\text { Mean }\end{array}$ & $\begin{array}{l}7428 \\
2654 \\
5041\end{array}$ & $\begin{array}{r}8414 \\
16219 \\
12317\end{array}$ & $\begin{array}{l}13846 \\
18118 \\
17358\end{array}$ & $\begin{array}{l}43.3 \\
56.7 \\
13.1\end{array}$ \\
\hline
\end{tabular}

Isaacs-Kidd net. This indicates the different catch efficiency of the different nets (Table 1 and 2). However, these nets were not used in the same areas. The Bongo nets were used at each of the oceanographic stations, and the Isaacs-Kidd mid-water net was used between the oceanographic stations. Cluster analysis, using data only obtained during the night (2000 to 0500), showed three groups related to the three latitudinal sampling areas. Two groups, the center (except one northerly station) and southern areas, were independent. The third group was dominated by all the stations of the northern zone and the nine stations of the center zone (these last were located in transects $\mathrm{C} 1$ and $\mathrm{C} 2$ near the coast), suggesting an overlapping of species from both areas (Fig. 3). A temperate California Current terminus assemblage dominated in the northern area, and a marginal ETP proliferator and an endemic ETP-adapted species dominated in the southern zone. The euphausiid community structure, and probably all the zooplankton community, showed strong latitudinal changes (Table 1 and 2). Nyctiphanes simplex was about two times more abundant during the day than at night at Ensenada (north) and Bahia Magdalena (south). At Punta Eugenia, this euphausiid had almost the same abundance, day or night. The rest of the species showed their highest abundance at night, suggesting night vertical migration to the surface (Table 2).

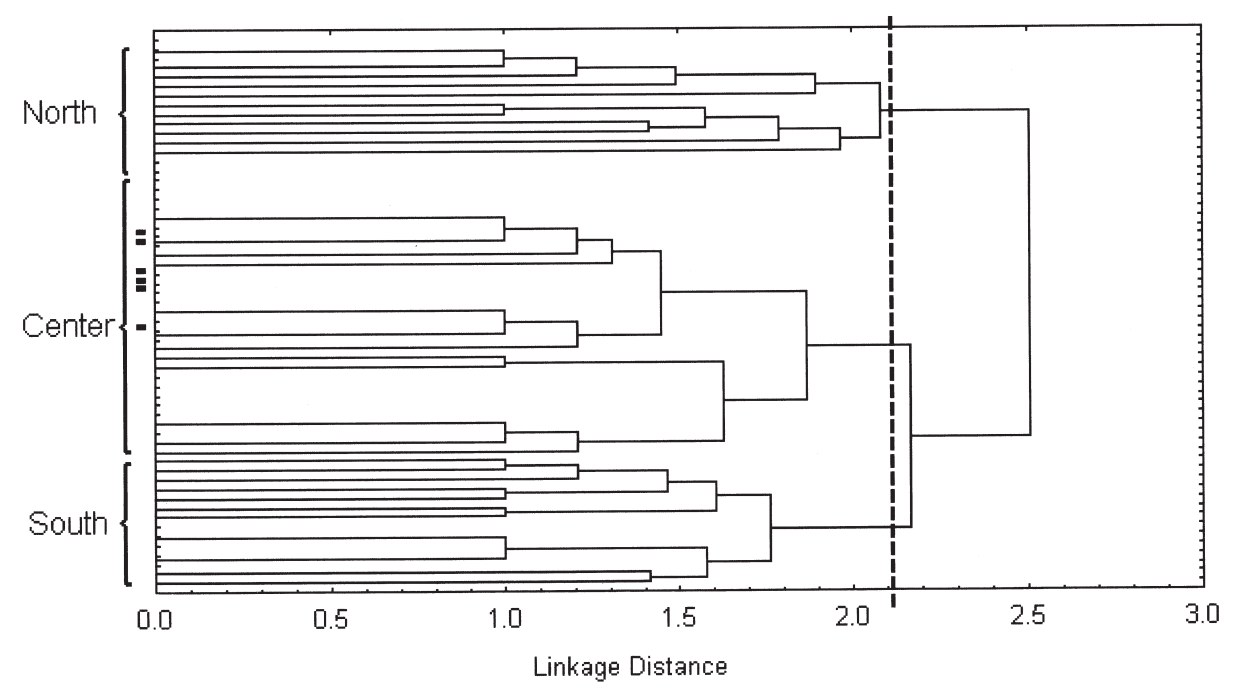

FIG. 3. - Cluster analysis (1-Pearson $r$ using weighted pair-group average) of the euphausiid species obtained with the Bongo net using samples (59 stations) obtained during the night (2000 to 0500) sorted by sampling stations (regional analysis). These groups were estimated considering a similarity level of about 2.1 (dashed line). Euphausia diomedeae was not included in the analysis because it was caught only during the day. Black points on the $y$-axis indicate the northern area stations. 
The zooplankton biomass from the $300-\mu \mathrm{m}$ mesh net trawls showed significant latitudinal changes (three-way ANOVA $P<0.05$ ) but no significant differences between offshore-inshore regions and daynight (three-way ANOVA $P>0.05$ ), indicating factors, such as patchiness and vertical distribution of the individual species during day and night tend to balance each other out. The zooplankton biomass obtained using the 500- $\mu \mathrm{m}$ mesh net showed significant latitudinal changes and day-night biomass changes (three-way ANOVA $P<0.05$ ). These did not show significant differences among the offshore-inshore regions (Three-way ANOVA $P>$ 0.05). Thus, two different-size zooplankton had strong latitudinal changes probably related to changes in the zooplankton community structure, and only zooplankton of $500 \mu \mathrm{m}$ showed day-night difference, suggesting an active diel vertical migration or net avoidance during daytime.

At particular SSLs, opening-closing net trawls were made to determine the euphausiid composition species above, within, and below the SSL. Nine euphausiid species were caught using this gear. $\mathrm{Nyc}$ tiphanes simplex (96\%) and E. eximia (3\%) (most of them in calyptope and furciliae stages) were the dominant species in most of these samples. The rest of the species contributed only $1 \%$ to the total abundance (E. tenera, S. affine, E. distinguenda, N. difficilis, N. tenella, N. gracilis, and E. pacifica, in decreasing abundance). In the north and center, a thermocline was not evident, however, the dominant species (N. simplex and E. eximia) were found pref-
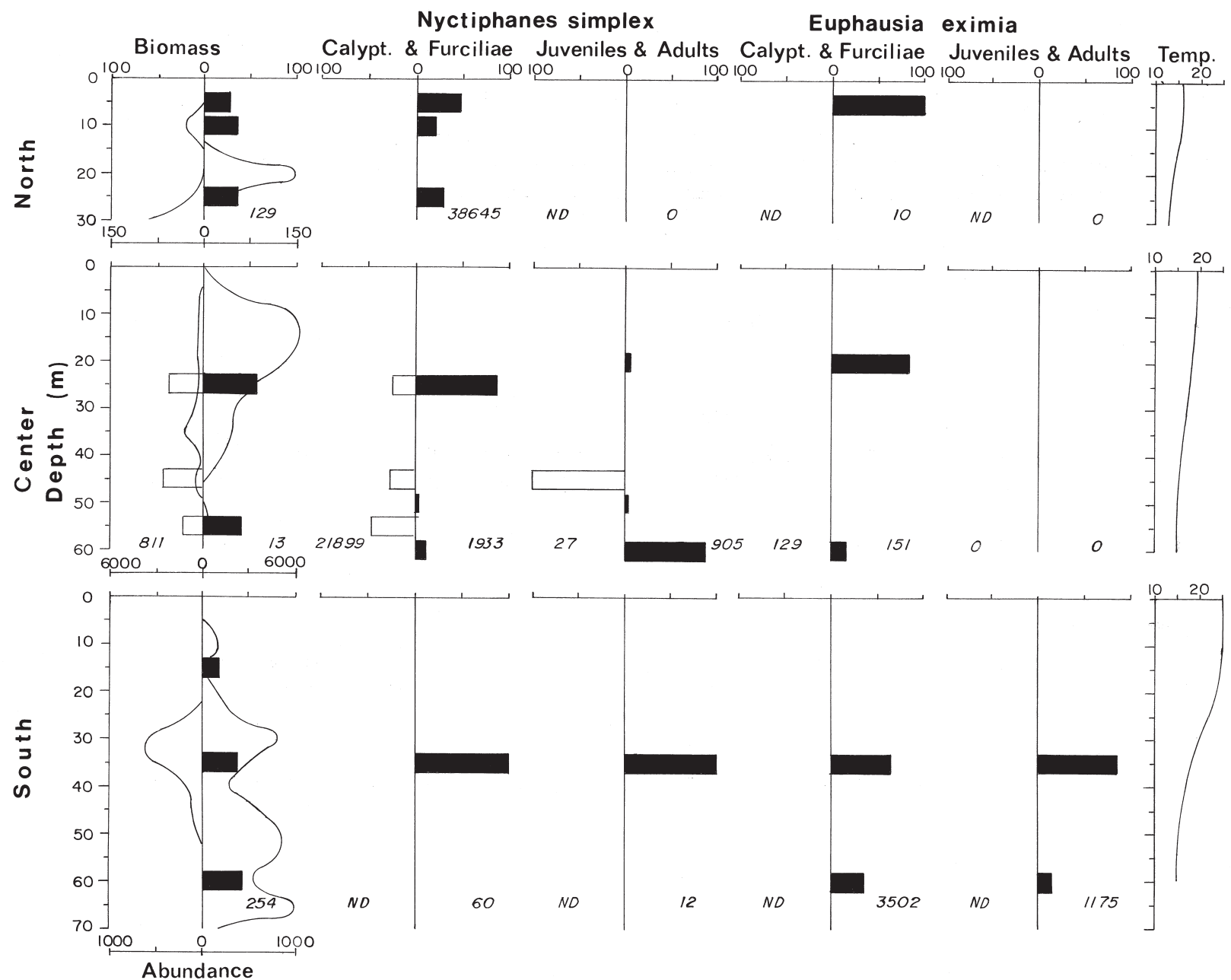

FIG. 4. - Vertical distribution of zooplankton biomass estimated by Bongo net (bars expressed in percentage, the italic number is the biomass expressed as $\mathrm{mL} 1000 \mathrm{~m}^{-3}$ ), zooplankton abundance measured by the echosounder (continuous line; echoes between -53 and $-57 \mathrm{~dB}$ expressed as ind $\mathrm{ha}^{-1}$ ), and vertical distribution of two of the most abundant euphausiid species Nyctiphanes simplex and Euphausia eximia in the three latitudinal regions expressed as relative abundance. White bars are day samples and black bars are night samples. The italic numbers are the total abundance integrated over all strata expressed as ind $1000 \mathrm{~m}^{-3}$. In the north and central areas, coastal stations are shown. In the southern area, the offshore stations where the SSL and these species were more abundant are shown. 

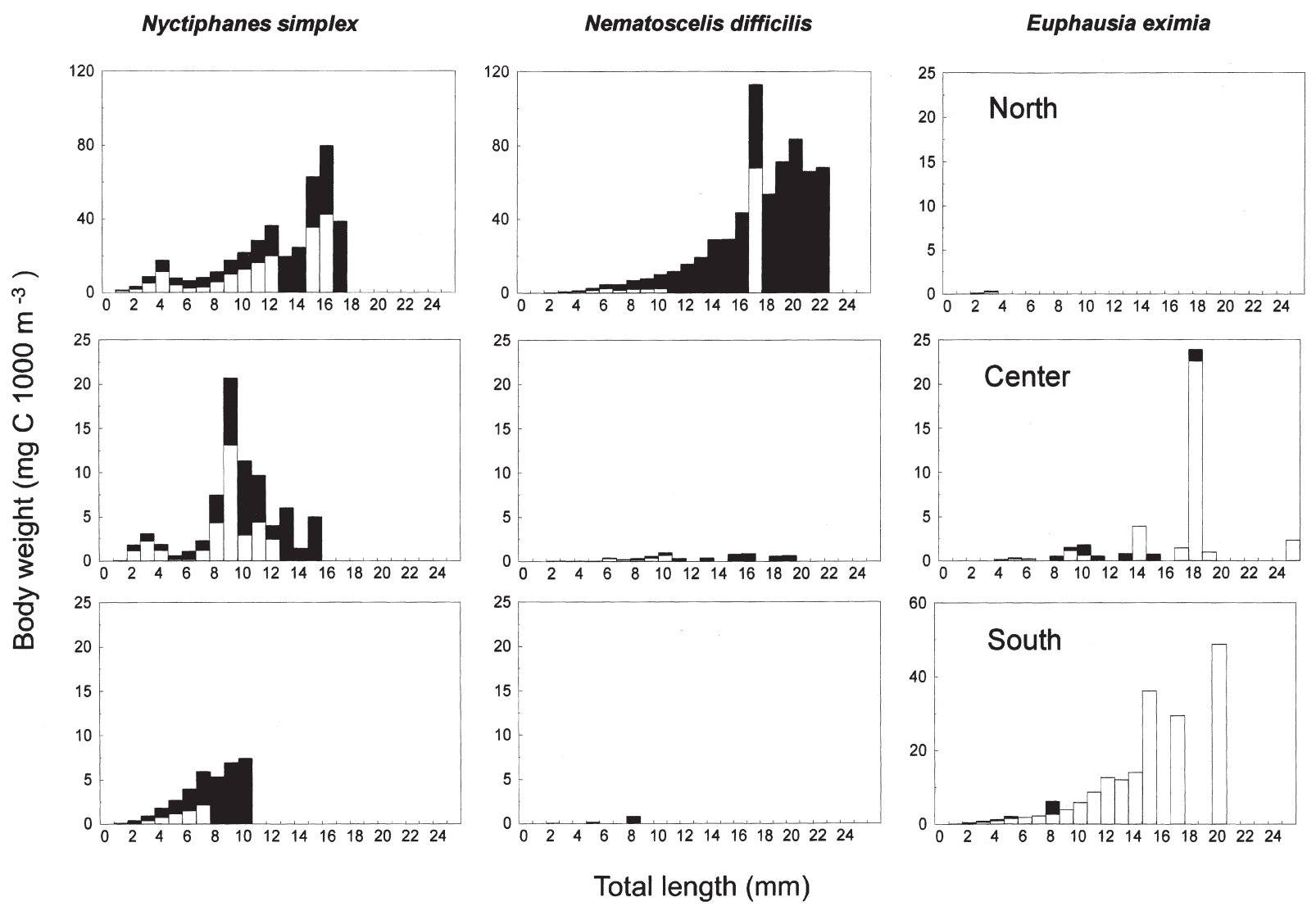

FIG. 5. - Average body weight by size of the three most abundant euphausiid species (Nyctiphanes simplex, Nematoscelis difficilis, and Euphausia eximia), in the three latitudinal regions expressed as body carbon weight $\left(\mathrm{mg} \mathrm{C} 1000 \mathrm{~m}^{-3}\right)$ calculated from dry-weight equations reported by Gómez-Gutiérrez and Robinson (1997) by assuming a carbon content of $45 \%$. White bars are samples obtaining during the day (0600 to 1900) and black bars are samples taken during the night (2000 to 0500).

erentially above $20 \mathrm{~m}\left(15\right.$ to $\left.17^{\circ} \mathrm{C}\right)$. Whereas, in the southern area, both species were found below the thermocline at about $35 \mathrm{~m}$ with a similar range of temperature $\left(15\right.$ to $17^{\circ} \mathrm{C}$ ) (Fig. 4). These patterns are similar to the vertical distribution of the zooplankton biomass estimated by the Bongo samples (volume displaced) and the abundance of echoes related to zooplankton shoals $(-53$ to $-57 \mathrm{~dB})$ estimated in layers 5-m thick (Fig. 4).

Each latitudinal region showed a different standing stock of the euphausiids expressed as mg C 1000 $\mathrm{m}^{-3}$ estimated for the three most abundant species (Fig. 5). Nyctiphanes simplex showed its highest biomass in the north with an integrated standing stock (the sum of the biomass of all the classes of

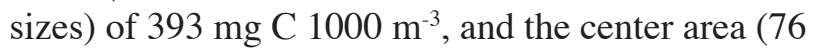
$\mathrm{mg} \mathrm{C} 1000 \mathrm{~m}^{-3}$ ) contributed to mainly by juveniles and adults. Relatively similar abundances were recorded during both day and night. A clear latitudinal cline of total length was observed with the larger animals in the north and the smaller animals in the south. This latter area had a population of smaller individuals observed mainly during the night $(<10$ $\mathrm{mm}$ total length and an integrated biomass of $35-\mathrm{mg}$ C $\left.1000 \mathrm{~m}^{-3}\right)$. Nematoscelis difficilis had an important standing stock only in the north during the night with an integrated standing stock of 643-mg C 1000 $\mathrm{m}^{-3}$. In the center and southern areas, its biomass was almost negligible with less than $6 \mathrm{mg} \mathrm{C} 1000 \mathrm{~m}^{-}$ 3. Euphausia eximia had an opposite trend showing its highest standing stock in the southern area (186 $\mathrm{mg} \mathrm{C} 1000 \mathrm{~m}^{-3}$ ) during the day, decreasing north-

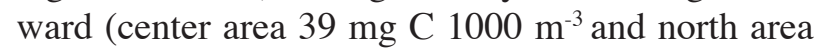
$<0.5 \mathrm{mg} \mathrm{C} 1000 \mathrm{~m}^{-3}$ ). In terms of carbon, the center area was the least productive of the three in euphausiid biomass partially caused by populations composed of relatively smaller individuals.

\section{Sound scattering layer characteristics recorded by the echosounder}

The northern transects had the highest concentrations of the SSL over the continental shelf; however, in the south, a tropical assemblage had smaller 

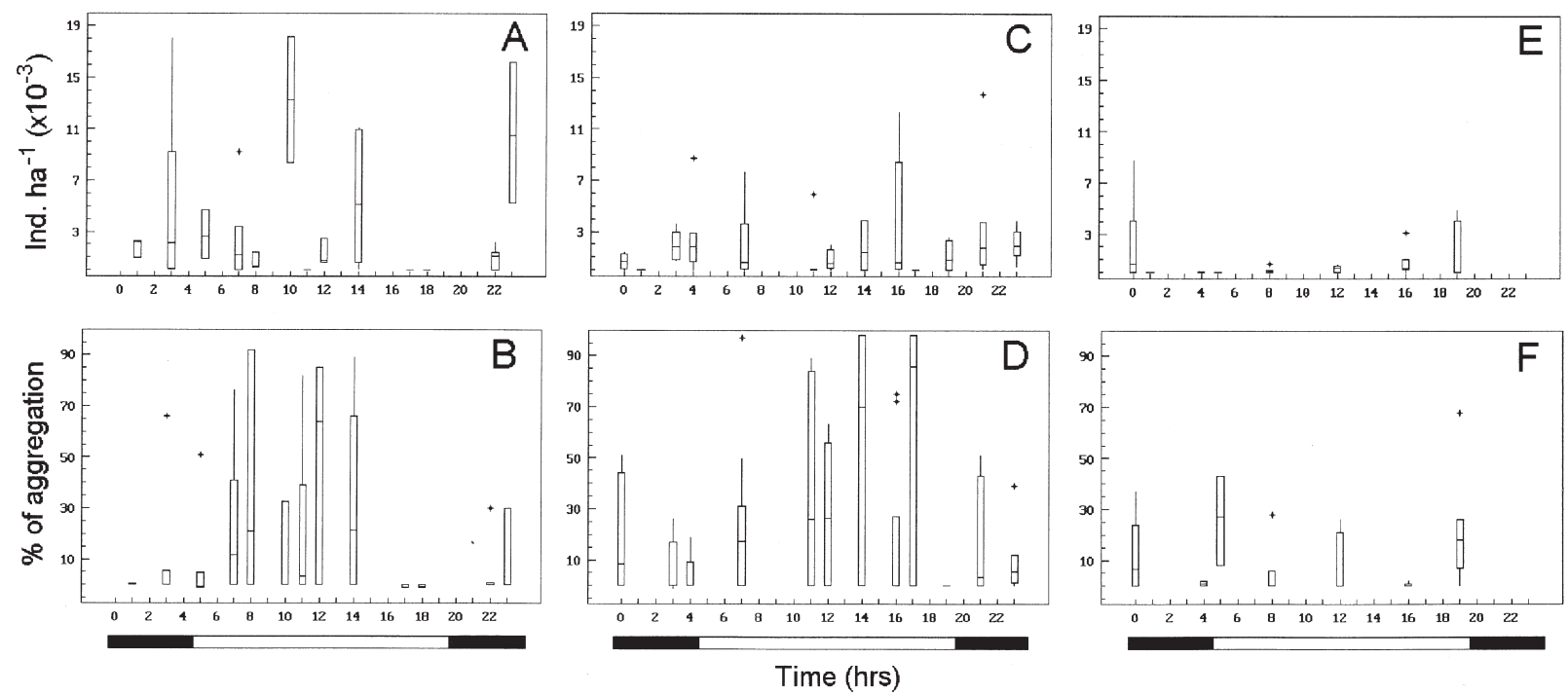

FIG. 6. - Box-and-whisker plot of the abundance (ind ha ${ }^{-1}$ ) and percentage of sound scattering layer compactness of zooplankton and nekton (echoes -53 to $-57 \mathrm{~dB}$ ) at $0-50 \mathrm{~m}$ over time of the north (Ensenada) (A and B), center (Punta Eugenia) (C and D), and in the south (Bahia Magdalena) (E and F).

shoals offshore. Ensenada (north) accounted for $55 \%$, and Punta Eugenia (center) accounted for $32 \%$ of the total echoes recorded. Only about $13 \%$ were recorded in the southern area (Bahia Magdalena) (Table 3). Diel zooplankton backscatter showed Ensenada and Punta Eugenia to be the regions with the highest abundance in the 0- to 50-m layers (Fig. $6 \mathrm{a}$ and $\mathrm{c}$ ). The southern sector (Bahia Magdalena) had very low abundance with its highest abundance occurring during the night (Fig. 6 e). No significant differences were found between day and night backscattering recorded hydroacoustically in the three latitudinal regions (Kruskal-Wallis test; $P>$ 0.001 ). The daily variation of percentage of compactness indicated that in the Ensenada region very concentrated SSLs were found during the night in the 0- to 50-m layer (Fig. 6 b). At Punta Eugenia, the
SSLs were very compact during both day and night, particularly between 1100 and 2100 (Fig 6 d). At Bahia Magdalena, we found the lowest percentage of compactness $(<50 \%)$ of the SSL. Within the 0 - to 50-m depth, the highest compactness was found during the night. SSL distribution in this region was extremely patchy, resulting in a skewed frequency distribution of density (Fig. $6 \mathrm{f}$ )

The size and shape (elongation = length/depth) of the SSL was obtained from the echogram visualization. The size was estimated from each echogram based on the ship's speed (11 knots) and time spent along the transect. In the northern region (EnsenadaPunta Baja) and the center region (Punta EugeniaBahia Asuncion), the zooplankton shoals hydroacoustically recorded were large and dense (mean sizes were 10- and 7-km long with a mean compact-

TABLE 4. - Frequency of records of the zooplankton patches per inshore-offshore regions. Average of the variables (length, depth, and elongation) of the scattering layer recorded hydroacoustically $(200 \mathrm{kHz})$ by latitudinal zone using all target strength range ( -32 to $-57 \mathrm{~dB})$. The standard deviation is show in parentheses. Echograms showed that no animal aggregations were neglected.

\begin{tabular}{|c|c|c|c|c|c|c|c|}
\hline \multirow[t]{2}{*}{$\begin{array}{l}\text { Zone and transects } \\
\text { analyzed }\end{array}$} & \multirow[t]{2}{*}{ Time } & \multicolumn{3}{|c|}{$\begin{array}{c}\text { Frequency of positive SSLs } \\
\text { per region }\end{array}$} & \multirow[t]{2}{*}{$\begin{array}{l}\text { Length of the } \\
\text { SSL m }\end{array}$} & \multirow[t]{2}{*}{$\begin{array}{l}\text { Depth of } m \\
\text { the SSL }\end{array}$} & \multirow[t]{2}{*}{$\begin{array}{r}\text { Elongation } \\
\text { Length/Depth }\end{array}$} \\
\hline & & Neritic & Slope & Oceanic & & & \\
\hline North 2 and 3 & $0800-1400$ & 5 & 1 & 4 & $6663(4425)$ & $24(15)$ & 282 \\
\hline North 2 and 3 & $2200-0700$ & $\begin{array}{c}6 \\
44 \%\end{array}$ & $\begin{array}{c}4 \\
20 \%\end{array}$ & $\begin{array}{c}5 \\
36 \%\end{array}$ & $10100(4588)$ & 35 (17) & 287 \\
\hline Center 1 to 4 & 0800-1900 & 7 & 2 & 3 & 4084 (3788) & $33(20)$ & 124 \\
\hline Center 1 to 4 & $2000-0700$ & $\begin{array}{c}13 \\
37 \%\end{array}$ & $\begin{array}{c}7 \\
33 \%\end{array}$ & $\begin{array}{c}5 \\
30 \%\end{array}$ & 7148 (4087) & $42(22)$ & 170 \\
\hline South 1 and 2 & 0800-1900 & 1 & 1 & 6 & $5139(2684)$ & $30(15)$ & 174 \\
\hline South 1 and 2 & 0000-0500 & $\begin{array}{c}2 \\
21 \%\end{array}$ & $\begin{array}{c}0 \\
7 \%\end{array}$ & $\begin{array}{c}4 \\
72 \%\end{array}$ & $5012(2480)$ & 37 (13) & 136 \\
\hline
\end{tabular}




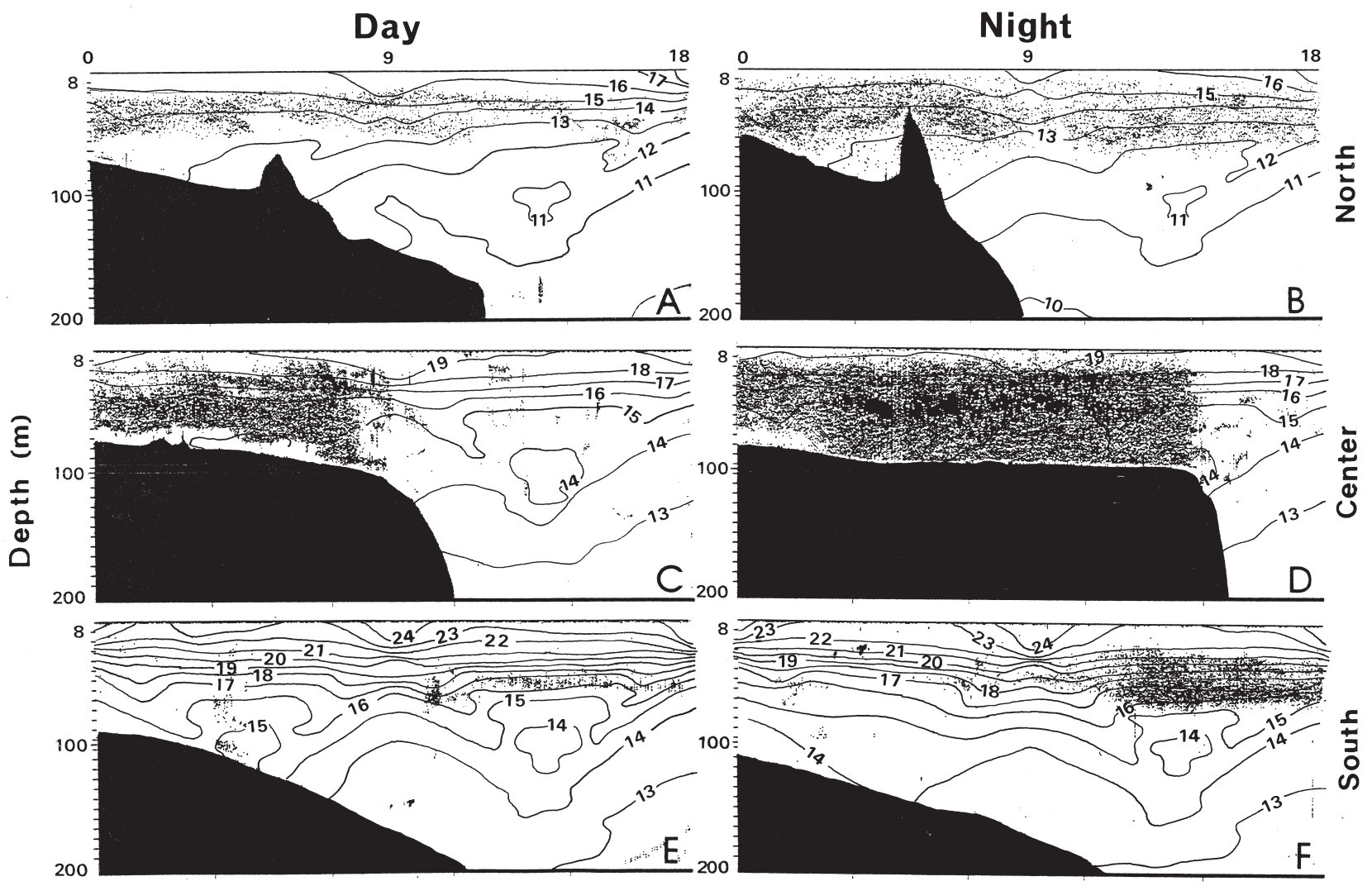

FIG. 7. - Comparison of three typical scattering layers recorded hydroacoustically in the three latitudinal regions along the west coast of Baja California during the day and night and superimposed over sea temperature profiles. Echograms included all target strength ranges (-32 to $56 \mathrm{~dB}$ ). North (transect N3) in day, 1006 (A) and night, 2310 (B); center (transect C4) in day, 0648 (C) and night, 0019 (D), and south (transect S2) in day, 1225 (E) and night, 0010 (F). The x-axis shows the length of the transect expressed as kilometers.

ness of $15 \%$ and $19 \%)$. The shoals were found to be mainly of the neritic species Nyctiphanes simplex and the temperate species Nematoscelis difficilis, Euphausia pacifica, and Thysanoessa spinifera. In the southern area, in the smaller and dispersed patches (mean size 5-km long and $11 \%$ compactness), we recorded tropical species, Euphausia eximia, E tenera, and E. distinguenda, which presumably did not form swarms, with $N$. simplex in lower abundance (data from Bongo nets), found at night (Table 2).

Representative echograms (all target-strength ranges included) during the day and night along the three latitudinal zones are shown in Figure 7. Targetstrength analysis indicated that pelagic fish were present within the zooplankton layer. The northern zone had long patches over the coastal shelf during the day, increasing in size and density during the night in the inshore and offshore areas (Fig. 7 a, b). In the center area, a dense shoal dominated by the decapod red crab (Pleuroncodes planipes) had extraordinary abundance (evidenced by Isaacs-Kidd mid-water samples) and compactness over the coastal shelf both day and night (Fig. 7 c, d). A high acoustic intensity in the zooplankton-red crab inshore patches suggests this layer is not homogeneous, probably as a result of the presence of fish schools within the zooplankton patches. In the southern area, the smallest patches were found in the offshore area with lower compactness (Fig. 6 e, f). North to south changes in patch structure was caused by strong latitudinal changes in physical oceanography that affect the species success at each region.

\section{DISCUSSION}

Sound-scattering-layer dynamics and euphausiid community structure obtained via the Isaacs-Kidd and Bongo nets showed a strong latitudinal cline during the autumn. According to Gómez-Gutiérrez and Robinson (1997), the euphausiid abundance and the biomass of macrozooplankton $(>1000 \mu \mathrm{m})$ were 
more important in the northern area than in the south during December 1993 along the west coast of Baja California, suggesting a recurrent latitudinal trend found during the second part of the year. Our data showed a 300- and 500- $\mu \mathrm{m}$ zooplankton biomass also had a significant latitudinal cline in its abundance and in the carbon content for three of the most abundant euphausiid species. This work tests the hypothesis that euphausiid community structure changes are parallel to morphological characteristics of the scattering layer where they live. The temperate euphausiid assemblages inhabit larger and more concentrated SSLs found mainly over the coastal shelf in the northern and central area. In these regions, the neritic euphausiid Nyctiphanes simplex, which frequently forms dense surface swarms, had its highest abundance over the continental shelf in the upper 25 meters (within and above a weak thermocline). Hydroacoustic measurements made for each five-meter depth also showed the highest abundance near the surface. In the southern region, the dispersed-offshore SSLs were dominated by a tropical pelagic assemblage of species like Euphausia eximia, E. distinguenda, and E. tenera. Euphausia eximia demonstrated its highest abundance below a strong thermocline $>30-\mathrm{m}$ deep, and the rest of the zooplankton and nekton (recorded hydroacoustically) remained also in deeper layers. These latitudinal trends are reasonably constant unlike the diel variability observed in the SSLs appearance caused by the 24-h vertical migration reported by Robinson and Gómez-Gutiérrez (1998). Latitudinal changes in $N$. simplex growth production was reported by Gómez-Gutiérrez et al. (1996), supporting the idea that the southern region is less productive than northern ones, and the SSLs are less dense and smaller along the southern part of Baja California. Estimations of the standing stock expressed as the carbon content of three of the most abundant euphausiid species indicate that the northern area is at least four times more productive than the southern area, showing different productivity between these two environments.

Petigas and Levenez (1996) made an echogram coding of fish schools according to the morphology of the echo traces, describing nine types. In this study, because we are describing whole SSLs with multispecies clusters instead of monospecies fish schools, we were unable to do a detailed description of these structures. However, we were able to discern the difference in the SSL in a temperate and a tropical assemblage. Horizontal length and relative acoustic density of the layer decreased with increasing thermocline gradients. Thus, the patchiness of whole zooplankton and nekton was less intense where vertical gradients were strong. This is contrary to the results of Barange (1994) where a strong degree of physical forcing and cross-shelf activity along a frontal zone affected the intensity of patchiness in the Benguela upwelling system. Robinson et al. (1997) reported a similar dispersed offshore SSL in the southern region (Bahia Magdalena) in December 1993, dominated by E. eximia, the red crab Pleuroncodes planipes, and the mesopelagic fish Vinciguerria lucetia, indicating that this is a recurrent feature of the SSL dynamics in this southern area during the autumn.

Gómez-Gutiérrez (1995) demonstrated that $N$. simplex and E. eximia have different inshore-offshore life maintenance strategies showing their core distribution to be inshore (N. simplex) and offshore (E. eximia). Hydroacoustic results obtained in the present work suggest that other zooplanktonic and nektonic species have similar inshore-offshore distribution preferences. The shape and patchiness properties of zooplankton can vary widely in different community structures, and as a result, the acoustic scattering properties vary accordingly. Significant inshore-offshore differences were found in the community structure and abundance estimated by Bongo net samples and hydroacoustic measurements along the peninsula, suggesting behavioral maintenance strategies of some dominant zooplankton and nekton species. The vertical migratory behavior of several zooplankton species (i.e. the euphausiids E. pacifica and $N$. simplex, clupeidae fish larvae, and other neritic species) may help them avoid offshore flow on the surface like other zooplankton species in areas dominated by coastal upwelling and complex advective processes in the California Current System.

Using conventional nets, Wiebe (1970) provided one of the first direct estimates of zooplankton patch size, estimating a median patch length of between 23 and $27 \mathrm{~m}$ during daylight and between 66 and $110 \mathrm{~m}$ during the night and concluded that aggregations were physically induced. Previous studies using sophisticated hydroacoustic devices $(307-\mathrm{kHz}$ acoustic Doppler current profiler ADCP and a Simrad EK-500 split-beam echosounder $120 \mathrm{kHz}$ ) reported wide gaps between zooplankton patches (Smith et al., 1989) suggest that the capacity and frequency of the echosounder used are critical to an adequate interpretation of the patch formation 
process. For example, Barange (1994), using a Simrad EK-400 38-kHz echo sounder at the Agulhas bank (South Africa), estimated that zooplankton patches are relatively long $(71 \mathrm{~m})$ and thin $(5 \mathrm{~m})$, and they are slightly larger than horse-mackerel patches.

Our estimations of the zooplankton-nekton shoaling (no patchiness sensu Ritz, 1994) are currently too coarse; however, they are good enough to prove that the SSL morphological variability is a function of the community structure. Schoenherr (1991), although his main goal was to shown a relation between the blue whale (Balaenoptera musculus) and the temperate euphausiid (Thysanoessa spinifera) distribution, describes the deep scattering layer in the Monterey submarine canyon $\left(37^{\circ} \mathrm{N}\right)$, reporting that the deep scattering layers were 1- to 2$\mathrm{km}$ wide with the thickest patches concentrated at depths of 130-150 m located near the shelf break. His echograms (echosounder working with a frequency of 100-200 kHz) showed a similar SSL-morphological appearance similar to the SSL recorded at our north and center area and those reported by Robinson and Gómez-Gutiérrez (1998) near Ensenada $\left(30^{\circ} \mathrm{N}\right)$ during July 1995 , where SSLs were dominated by the euphausiids Nyctiphanes simplex and Euphausia pacifica.

Our findings represent a different SSL dynamic pattern to that described for offshore regions, which were done in regions of water depths of about 1,000 to $4,000 \mathrm{~m}$. In offshore regions, depth distributions, vertical and horizontal dimensions of the aggregations, and gaps between aggregations are relatively consistent (Smith et al., 1989). Our data over the continental shelf suggest a more variable SSL patchiness dynamic than in the oceanic environment. Hydroacoustical records were, in fact, from all zooplankton and nekton assemblages, but we only analyzed the euphausiid component. Therefore part of the echoes recorded could be animals detected with different patchiness behavior and vertical migration than that of the euphausiids. Probably this was the cause of several mismatches in the horizontal distribution of the biomass estimated via Bongo nets and Isaacs Kidd midwater nets, and recorded using the echosounder.

The Spearman rank correlation between abundance of zooplankton recorded by the echosounder vs. temperature and salinity obtained via the CTD in the column water showed, in general, no significant correlation, $P>0.001 ; r_{s}=-0.6190$ (north), $r_{s}=$ 0.7714 (center), and $r_{s}=-0.800$ (south), suggesting that other physicochemical variables or behavior can have an important role in the vertical distribution of the SSL. Most euphausiids were caught with different net gear during the night in the 5- to 50-m layer where acoustic records were also more frequent. They migrated to deeper layers during the day crossing the thermocline and halocline. This suggests a typical vertical migration to the surface during the night (as found in the north and center areas) with little relation to the physicochemical variables. A relation between the appearance of a SSL and environmental variables alone may not produce any new insight.

According to Bongo net samples, Nyctiphanes simplex was found to be about two times more abundant during the day than at night at Ensenada (north) and Bahia Magdalena (south), probably because this species tended to form dense surface swarms during the day in environments favorable to reproduction and feeding. In the center area, there was a similar abundance during the day and night. Dense euphausiid swarms were detected and showed highly concentrated swarms near the seabed during the night (Robinson and Gómez-Gutiérrez, 1998) suggesting that this species displays very different diel vertical patterns as a function, possibly, of the season and local environmental conditions. Regions that were dominated by omnivorous temperate species like E. pacifica and $N$. difficilis along with $N$. simplex (these species have highly setose maxillae, nearly equal length periopods, disproportionately large pars molaris on the mandible, and a feeding basket displaying mainly omnivorous feeding habits) were associated with SSLs with the highest values of compactness in the 0 - to 50- m layer, suggesting that these temperate species form dense swarms (Robinson and Gómez-Gutiérrez, 1998). A tropical assemblage dominated by carnivorous species (the first and second pair of periopods elongated to form grasping legs, a small par molaris relative to the incisor, and a coarser setose feeding basket) like E. eximia, E. distinguenda, and E. tenera, was found within a relatively small SSL 4-km).

The primary instrumental shortcomings originate in HADAS' ability as an echo-counter and the lack of resolution of our echosounder $(200 \mathrm{kHz})$ to record animals smaller than $7 \mathrm{~mm}$, which includes most of the meso- and macrozooplankton community structure. In addition, because this device uses a single-beam, it was not possible to estimate the single target strength. Nevertheless, with new methods like dual-beam or split-beam for acoustical process- 
es at work in the ocean's interior, ecologists can begin to gain insights into the processes associated with zooplankton and nekton patch dynamics. These types of studies should be made in different seasons to test our hypothesis concerning the importance of community structure on SSL dynamics and the probable homogeneity of SSL dynamics during spring-early summer in the southern portion of the California Current System.

\section{ACKNOWLEDGEMENTS}

Thanks are extended to the students from the Laboratory of Fisheries Ecology UNAM, to the RV 'El Puma' crew for assistance and comradeship at sea, and to Dr. Ellis Glazier, CIBNOR, for his editorial help with the English text. We thank Dr. Torfinn Lindem for comments and advice about the abilities of HADAS software. This research was supported by funds provided by the Dirección de Estudios de Posgrado e Investigación (DEPI 966584, 970123, and 988002) and by the Consejo Nacional de Ciencia y Tecnología (CONACyT 940511, N511N9108). The authors J.G.-G., C.J.R., and V.A.-F. are supported by Sistema Nacional de Investigadores (SNI), and the first author also is supported by a Comisión de Operación y Fomento Actividades Acádemicas del Instituto Politécnico Nacional (COFAA) fellowship.

\section{REFERENCES}

Barange, M. - 1994. Acoustic identification, classification and structure of biological patchiness on the edge of the Agulhas bank and its relation to frontal features. S. Afr. J. mar. Sci., 14: 333-347.

Brinton, E. - 1962. Variable factors affecting the apparent range and estimated concentration of euphausiids in the North Pacific. Pac. Sci., 16: 374-408.

Brinton, E. - 1979. Parameters relating to the distribution of planktonic organisms, especially euphausiids in the Eastern Tropical Pacific. Prog. Oceanogr., 8: 125-189.
Craig, R.E. and S.T., Forbes. - 1969. A sonar for fishing counting. FiskDir. Skr., Ser. Havunders., 15: 210-219.

Gómez-Gutiérrez, J. - 1995. Distribution patterns, abundance and population dynamics of the euphausiids Nyctiphanes simplex and Euphausia eximia in the west coast of Baja California, México. Mar. Ecol. Prog. Ser., 119: 63-76.

Gómez-Gutiérrez, J. and C.J. Robinson. - 1997. Circadian biomass and abundance changes of five euphausiids along the west coast of Baja California Mexico, December 1993. Sci. Mar., 61: 2735 .

Gómez-Gutiérrez, J., R. Palomares-García and D. Gendron. - 1995. Community structure of the euphausiids populations along the west coast of Baja California, México during the weak ENSO 1986-87. Mar. Ecol. Prog. Ser., 120: 41-51.

Gómez-Gutiérrez, J., De Silva-Dávila, R, Lavaniegos, E.B. - 1996. Growth production of the euphausiid Nyctiphanes simplex at the coastal shelf off Magdalena Bay, Baja California Sur, México. Mar. Ecol. Progr. Ser. 138: 309-314.

Isaacs, J.D. and R.A. Schwartzlose. - 1965. Migrant sound scatters: interaction with the sea floor. Science. 150: 1810-1813.

Lindem, T. and H.A. Houri. - 1988. Hydro Acoustic Data Acquisition System HADAS. Department of Physics, University of Oslo, P. Box 0316. Oslo Norway, 4 pp.

MacLennan,D.N. and E.J., Simmonds. - 1992. Fisheries Acoustics. Chapman \& Hall, Fish and Fisheries Series, London.

Massé, J., C. Koutsikopoulos and W. Patty. - 1996. The structure and spatial distribution of pelagic fish schools in multispecies clusters: an acoustic study. ICES J. Mar. Sci., 53: 155-160.

Misund, O.V. - 1993. Dynamics of moving masses: variability in packing density, shape, and size among herring, sprat, and saithe schools. ICES J. Mar. Sci., 50: 145-160.

Misund, O.V., A. Anglen and E. Frfnaes. - 1995. Mapping the shape, size, and density of fish schools by echo integration and a high-resolution sonar. ICES J. Mar. Sci., 52: 11-20.

Parsons,T.R., Y. Maita, and C.M. Lalli. - 1984. A manual of chemical and biological methods for sea water analysis. Pergamon Press, Oxford.

Petigas, P. and J.J. Levenez. - 1996. Spatial organization of pelagic fish: echogram structure, spatio-temporal condition, and biomass in Senegalense waters. ICES J. Mar. Sci., 53: 147-153.

Ritz, D.A. - 1994. Social aggregation in pelagic invertebrates. $A d v$. Mar. Biol. 30: 155-216.

Robinson C.J. and J. Gómez-Gutiérrez. - 1998. Daily vertical migration of dense scattering layers related to shelf-break area in the northwest coast of Baja California, México. J. Plankt. Res., 20(9): 1679-1697.

Robinson, C.M., J. Gómez-Gutiérrez and F.V. Arenas - 1997. On the structure of a scattering layer in the southwest coast of Baja California using net trawl samples and hydroacoustic. Cienc. Mar. Baja Calif. Méx., 23(1): 141-154.

Smith, P.E., M.D. Ohman and L.E. Eber. - 1989. Analysis of the patterns of distribution of zooplankton aggregations from an acoustic Doppler current profiler. Calif. Coop. Ocean. Fish. Invest. Rep., 30: 88-103.

Schoenherr, J.R. - 1991. Blue whales feeding on high concentrations of euphausiids around Monterey submarine canyon. Can. J. Zool., 69: 583-594.

Wiebe, P.H. - 1970. Small scale spatial distribution in oceanic zooplankton. Limnol. Oceanogr., 15: 205-217.

Scient. ed.: M. Alcaraz 